\title{
Applications of ARTIST for advanced telematics services
}

\author{
P. Isola ${ }^{1}$, L. Marasco ${ }^{1}$, A. Piccolo ${ }^{2} \&$ V. Galdi ${ }^{2}$ \\ ${ }^{I}$ Dipartimento per la Programmazione ed il Coordinamento dello \\ Sviluppo del Territorio, il Personale e i Servizi Generali, \\ Direzione generale per la programmazione e i programmi europei, \\ Ministero delle Infrastrutture, Italy \\ ${ }^{2}$ Dipartimento di Ingegneria dell'Informazione ed Ingegneria Elettrica \\ Università degli Studi di Salerno, Italy
}

\begin{abstract}
Telematics, also known as ICT (Information and Communications Technology), integrates telecommunications and informatics technologies to send, receive and store information via telecommunication devices. The ITS (Intelligent Transport System) is the application of telematics to the transportation area so that it allows the provision of advanced services in the mobility area in order to reinforce the efficiency, safety and effectiveness of the transportation systems.

More efforts have been carried out in recent years to support the spreading of ITS and many projects have been financed in the world and, in particular, in Europe. One of the most critical problems which has arisen in these experiences is the lack of interoperability amongst the ITS able to guarantee the definition of new services and the development of the existing ones. To solve this problem, which represents an obstacle to the widespread use of the ITS, the European Commission has promoted the development of a common platform for ITS in Europe.

In this scenario the Italian Ministry of Infrastructure and Transport (MIT) have in 2003 pointed out ARTIST, the Italian ITS architecture. ARTIST represents one of the meaningful experiences in progress concerning the definition of a shared ITS architecture, able to promote the development of next generation telematics services.

In this paper two ITS projects developed by the authors at the University of Salerno based on ARTIST architecture are shown.

Keywords: ITS - Intelligent Transport Systems, telematics, infomobility systems.
\end{abstract}




\section{Introduction}

Intelligent Transportation Systems (ITS), which are the integration of telecommunications and informatics technologies to send, receive and store information via telecommunication devices applied to the transport systems, represent one of the more effective solutions to support sustainable growth of mobility demand [1-3].

ITS, in fact, supplying advanced telematics services, allow better use of existing mobility resources, sustaining modal readdressing, reducing accidents and improving the efficiency of transport.

In particular, from ITS a great support is expected to improve road safety to reduce the environmental impact of mobility, mainly in countries where it is difficult to build new infrastructures, both for the environmental problems and for lack of funds, helping the governments to achieve the two priority objectives fixed by the European Commission to be attained by 2010 [1]:

- $\quad$ to promote a regulated competition between modes;

- to reduce deaths due to road accidents.

More efforts have been carried out in recent years to support the diffusion of ITS and many projects have been financed in the world [4-6]. The experiences have highlighted that the lack of interoperability amongst the ITS systems represents an obstacle to widespread use of ITS. To develop open, shared, modular, interoperable and upgradeable ITS able to guarantee the definition of new services and the growth of existing ones, the European Commission (EC) has promoted in the last ten years many projects, like Karen and FRAME [7, 8], defining common behaviours of the ITS European platform. FRAME, in particular, is the European ITS Framework Architecture [8, 9] that defines a common platform to develop national telematics architectures in Europe. In a few years the Karen and FRAME projects have generated many national telematics architectures: ACTIF (Architecture Cadre pour le Transports Intelligents en France) in France, now at the $5^{\text {th }}$ release, TTS-A in Austria, TEAM (Telematics Eurodigibus And Mobility) in the Czech Republic and ARTIST in Italy [10-12].

The choice of the EC to develop a general framework, that guides the introduction of national telematics architectures instead of a common European ITS architecture, guarantees the availability of many solutions customized for the specific needs related to different geography, demographics and institutional arrangements.

In this context, ARTIST, the Italian ITS Architecture, plays a significant role. ARTIST $[12,13]$, issued in its first release in 2003, is an initiative of the Italian Ministry of Transports and Infrastructure with the aim to help and harmonize the development of the national market, achieving the integration of transport modes and ITS, both at a national and European level. To support the spread of ARTIST, the MIT have executed many protocol agreements with national institutions and universities to evaluate the ARTIST compliance of the ITS projects. 
In this paper some applications of ARTIST in the info-mobility area are proposed. The projects are developed by the authors of the Department of Electrical Engineering and Computer Science (DIIIE) at the University of Salerno as a demonstrator of research projects developed in the last two years. The projects are weighing by the Dipartimento per la Programmazione ed il Coordinamento dello Sviluppo del Territorio, il Personale e i Servizi Generali Direzione generale per la programmazione e i programmi europei of the MIT in order to highlight the main criticality related to the application of the ARTIST and of ARTIST's facilities.

The paper is organized as follows: in section 2 a brief description of the Italian Telematics Architecture is proposed, whereas in sections 3 two ITS projects carried out by the University of Salerno and based on the ARTIST architecture are shown.

\section{ARTIST: the reference architecture for ITS Italian projects}

To guarantee modularity and expandability of the IT systems pointing out efficient devices and services, aimed at satisfying users' needs and at promoting quality and competitiveness in the transportation system, the use of open telematics architectures is suitable. A telematics architecture for ITS, like ARTIST, the Italian one, defines, in fact, a common language for all the stakeholders involved in the design, implementation, management and use of a telematics system furnishing services in the transport area.

The ARTIST project comes from the National Plan for Transport and Logistics [2] and from the European projects Karen and FRAME, aimed at promoting the development of an efficient and interoperable transport system in Italy.

ARTIST's main objective is to provide public authorities, transport operators, infrastructure managers and private companies with general guidelines to simplify and improve in effectiveness and efficiency the design, the development, the management and the maintenance of ITS.

In order to guarantee the interoperability at least at a European level of the Italian telematics systems for transport, ARTIST has been developed in compliance with FRAME, the European Reference Architecture, and with the French National Architecture, ACTIF: in particular, ARTIST and ACTIF use the same language, representing an important step towards the ITS integration at a European level, and a model to be followed in other national projects.

The first version of ARTIST was released in March 2003 and it was the result of a structured development process where the most important national actors active in the ITS have been involved.

ARTIST, like other telematics architectures for transport, describes all the components of an ITS, how they interact and work together and what information they exchange.

The first element of ARTIST is the list of User Needs (UNs), which comes from the UNs of FRAME. Starting from the services required by the users coded in the UNs, ARTIST defines: 
- the functions able to satisfy the UNs;

- the functional relationships among the functions, represented by the information flows exchanged among them, that define the Logical Architecture of the ITS;

- the physical domains where the logical functions will be implemented, that define the Physical Architecture of the ITS;

- the organizational relationships among the different users involved in the development and management of ITS, that define the Organizational Architecture of the ITS.

Compared with the other ITS European architectures ARTIST contains some innovative elements, as extensions to some multimodality/intermodality aspects, especially concerning the Users' Needs and the Functional Architecture, and a new section related to the Organizational Architecture, based on a methodology that clarifies the roles and the responsibilities of the actors providing the services described by the Logical Architecture.

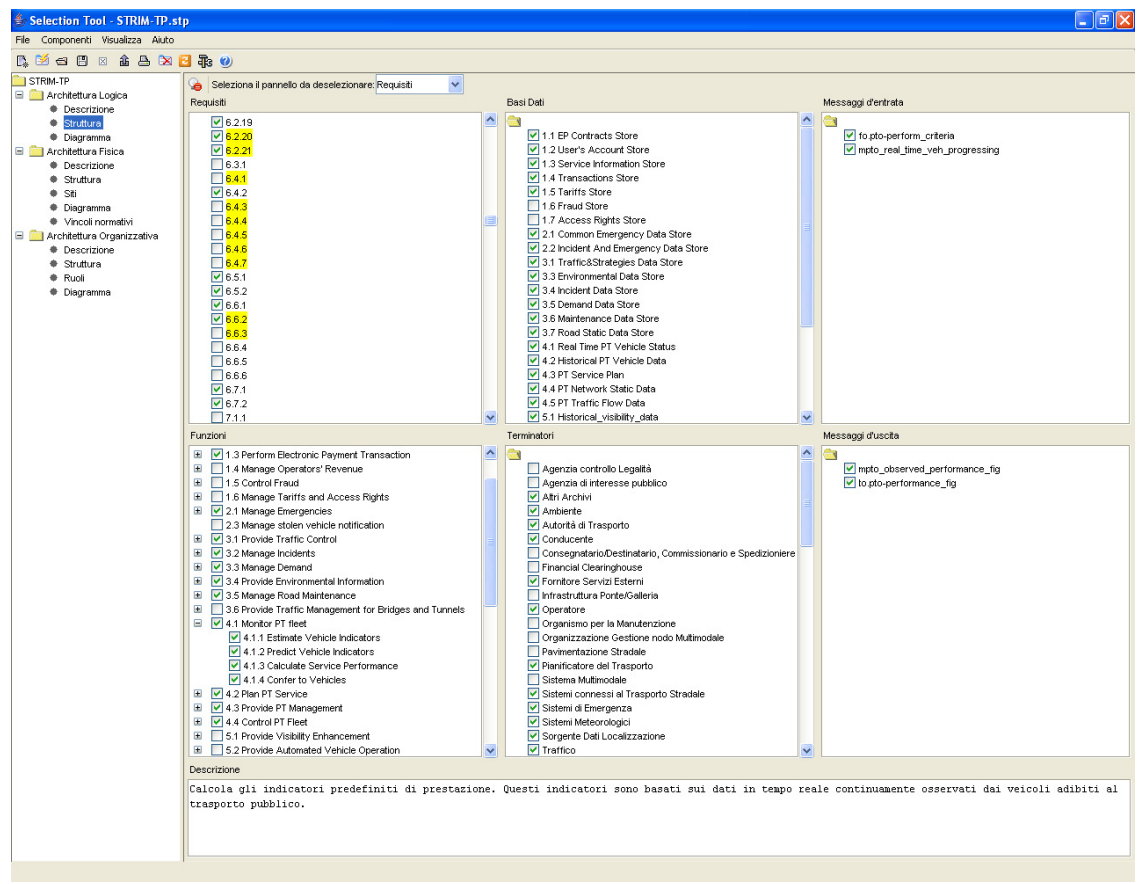

Figure 1: ARTIST's selection tool.

Finally, in order to promote a widespread use of the architecture, ARTIST furnishes a Navigation Tool (Selection Tool) based on an open source approach. The SElection Tool of Artist (SETA), which improves the architecture usability, has been fulfilled and provided on the ARTIST web site free of charge so as to support the designers in the ITS development. 
All these features can bring many benefits: ARTIST, in fact, is an open architecture and so it easily allows one to integrate new functions and update the existing ones conferring, in this way, modularity and expansibility to the IT systems.

Through ARTIST it is possible to point out efficient devices and services, aimed at satisfying users' needs and at promoting quality and competitiveness in the transportation system. It favours the integration of the ITS and services, allowing the final user to get continuously updated and reliable information on traffic conditions and transport services.

The great usability and the aforementioned advantage related to the architecture use have raised a growing interest in the technical and scientific communities. Moreover, a second architecture release, that takes into account all the experiences revealed in dozens of telematics projects carried out in the last two years, has been planned.

\section{Application of ARTIST}

Although ARTIST is a young architecture, many ITS applications are developing in Italy according to its guidelines [14]. Some of these activities are supported or monitored by the Italian Ministry of Infrastructure and Transports, which has promoted agreements with Institutional Boards and with Universities in order to favor ITS projects design and implementation in compliance with ARTIST.

In the following section, two projects developed by the University of Salerno in accordance with the ARTIST architecture are shown. In [15] a further telematics information project carried out by the authors at the University of Salerno, named SITUS-TP (Sistema Informativo Telematico dell'Università di Salerno per il Trasporto Pubblico) has been presented.

\subsection{STRIM-TP project}

STRIM-TP (Sistema Telematico Regionale Integrato per il Monitoraggio del Trasporto Pubblico) is an Integrated Telematics Information System developed by the researchers of the Electrical Engineering \& Computer Science Department - University of Salerno concerning public transport. The project, developed with the technical support of Mizar Automazione, is supported by the main public transport companies of the Regione Campania: A.IR., ANM, CSTP, CTP, MetroCampania NordEst (MCNE) and SEPSA. The system collects, combines and processes the data of about $70 \%$ of the Regione Campania public transport system (PTS) in an area with 5,7 million people and $13.595 \mathrm{~km}^{2}$, supplying telematics services to the users of the Campania PTS.

STRIM-TP monitors the fleets of public transport, relates the data acquired in real time with those referred to the planned and the programmed services, supplies information on the quality of the service and on the actual offer of mobility and gives advanced journey planning on the whole Campania based on the real time status of the public transportation system. 
The STRIM-TP architecture has been designed according to the ARTIST guidelines, guaranteeing interoperability, scalability and modularity, and focusing the attention on the organizational aspects related to the management of a multi-company telematics system.

The potential users of STRIM-TP are:

- Local public administration offices, that must monitor the service quality, to verify its compliance with the minimum QoS levels defined in the service contracts;

- Transport enterprises managers, interested in monitoring the service quality level, the network status and, in case of need, the critical issues in the mobility system in real time;

- Planners, both from public transport enterprises and from local public administration offices, interested in data related to the real territory mobility demand;

- Users, interested in getting information about the services supplied on the territory.

The identification of Telematics system users has allowed us to define the users' needs described in the table below.

Table 1: Main range sets and subsets for the STRIM-TP users' requirements.

\begin{tabular}{|c|c|}
\hline SETS & SUBSETS \\
\hline 2. Planning and Infrastructures & 2.1 Transport planning support \\
\hline \multirow{2}{*}{$\begin{array}{l}\text { 4. Electronic payment and financial } \\
\text { transactions }\end{array}$} & 4.1 Electronic financial transactions \\
\hline & $\begin{array}{l}4.2 \text { Transport/transit documents } \\
\text { management }\end{array}$ \\
\hline \multirow{2}{*}{ 5. Emergency } & 5.1 Emergency messages \\
\hline & 5.2 Alert signs \\
\hline \multirow{5}{*}{ 6. Information for the users } & 6.1 Information before travelling \\
\hline & 6.2 Information during travelling \\
\hline & 6.5 Economical Growth sustenance \\
\hline & 6.6 Demand management \\
\hline & 6.7 Social services \\
\hline \multirow{2}{*}{ 7. Traffic management } & 7.1 Traffic management \\
\hline & 7.3 Demand management \\
\hline 8. Driver's assistance & 8.3 Safety improvement \\
\hline \multirow{2}{*}{ 10. Public transport fleets for Passengers } & $\begin{array}{l}\text { 10.1 Collective transport } \\
\text { management }\end{array}$ \\
\hline & $\begin{array}{l}10.2 \text { Public transports with on- } \\
\text { request stops }\end{array}$ \\
\hline
\end{tabular}

Starting from the user needs definition, ARTIST provides the general guidelines suitable to identify the functions, the terminators (people and systems that interact with the telematics system) and the databases necessary to design the ITS, highlighting both the in-coming and the out-going data flows for each single element of the logical architecture of STRIM-TP. 
The latest phase of the STRIM-TP design process has dealt with the definition of the physical and organizational architecture that identifies the responsibility centers to which physical and functional sets refer. Each functional set is linked to a small number of functions able to meet the users' needs belonging to a certain responsibility the centre owner actor (enterprises, public administration offices, infrastructure owner).

The resulting distributed-intelligence architecture, modular and interoperable, is organized on three levels:

- field level;

- periphery level;

- centre level.

On the field level there are both long and short-ranged wireless communication devices and physical systems suitable to locate the vehicles, to monitor on-board systems and to acquire financial transaction data.

On the periphery-based level, we can identify systems fit to gather enterprise data coming from public transport (PT) fleets. In the organizational sample proposed, field and periphery-based devices management is assigned to the service suppliers who need data in real-time in order to support SAE and AVM services.

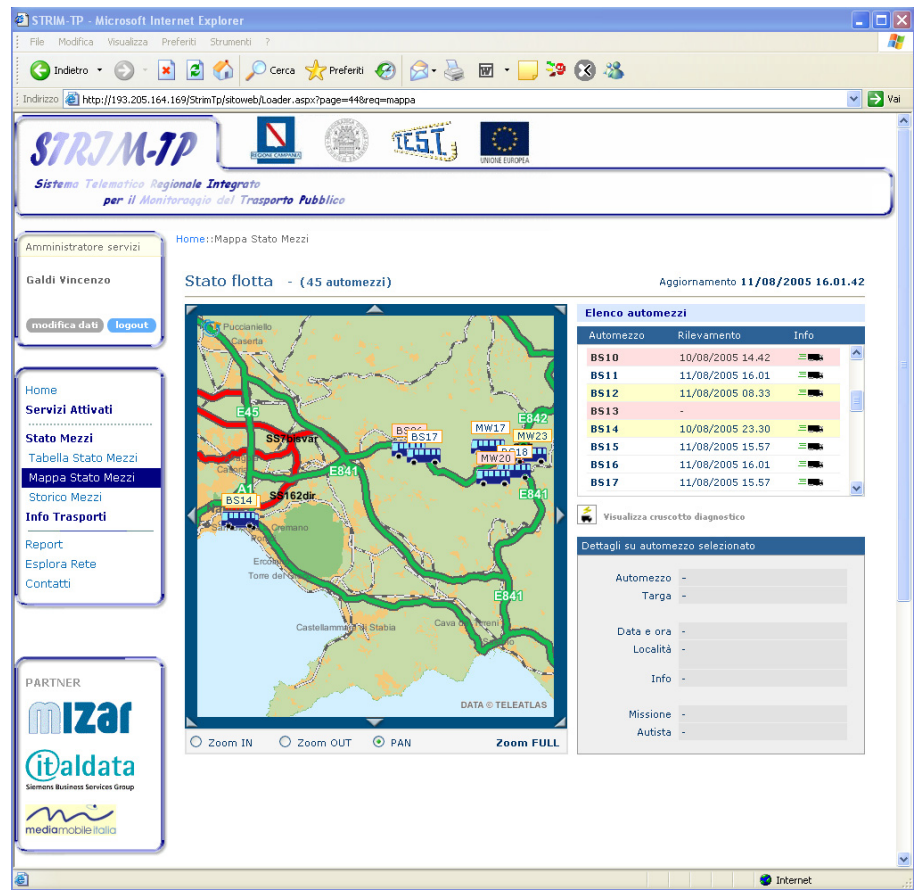

Figure 2: $\quad$ STRIM-TP portal. 
On the periphery-based level, beside the real-time data related to the service supplied, data concerning the programmed and the ordered service (which gathers those changes caused by an unforeseen event during planning) are available too.

STRIM-TP functions are reachable through a web portal as well. Access to these portal functions is handled by a policy that allows selective accesses for each user, following a "username/password" identification mechanism.

The portal offers public transport users both information about the transport availability updated in real-time and journey planning tools as well. The PT is presented as an integrated system, able to fit all the individual mobility needs. Once the user specifies his own transport requests, the system suggests a series of solutions linked to the current network availability: it supplies a service suitable to meet the mobility demand with a "door-to-door" supply, within a multi-enterprise viewpoint in the sphere of an integrated system for a regionwide public transport.

This information is either available in a text format or in a graphic GIS (Geographic Information System) format that contextualize the transport offer supplied to the territory.

Furthermore, a journey-planning, multimodal and multi-enterprise is also available that draws routes on the map of the Campania just by selecting on the map via the web the starting and the destination point, according to public transport availability on the whole Campania updated in real-time.

Information about the mobility supply on the regional territory is available for these users as well: by specifying an address, it is also possible to find out all the available stops around that point, all the bus lines passing by those stops and the next expected arrival times, according to the service planned and, if available, to the service status regularly updated. Besides, on the cartography the most significant Points of Interest (POI) in the area are shown as well.
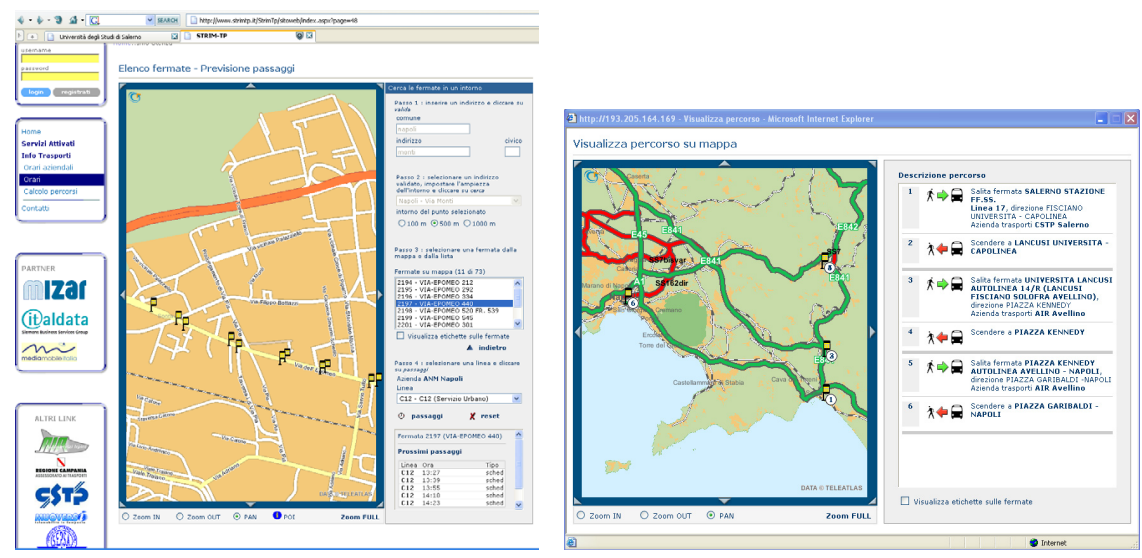

Figure 3: Journey planning. 
For the services planning managers in the services supplying transport enterprises, STRIM-TP makes available information about the main on-board systems functionalities, the GPS apparatus, the ticketing devices, the telematics devices and the main engine technical specifics (water temperature, round number per minute, current and average speed).

Transport means maintenance-related data is available for the means maintainers and owners too.

Moreover, for the programming, surveillance and control managers in the (regional, sub-regional, urban and sub-way) public transport services sector, STRIM-TP makes available a series of functions to elaborate the data gathered and to figure out the quality indexes, like the kilometres counter accuracy, the bus trips number, the trips not done, bus punctuality of a particular enterprise, punctuality and regularity of a specific service, monthly delay statistics, etc.

\subsection{SITI project}

The SITI - Safety in Tunnel Intelligent - is a research project from the "TRAIN" consortium, a joint public-private organization with National Research Centres (ENEA), Universities (Salerno's and Lecce's) and enterprises working in the transports area (Ansaldo Rail System Transports, Trenitalia, RFI, Uniontransporti, AnsaldoBreda, Reggiane Cranes and Plants, D'Appolonia, Bertolotti, etc...). The project has been financed by the Ministry of University and Scientific Research [16].

The project aim is to prevent and mitigate the effect of accidents in road and railway tunnels by using ITS to develop a dynamic tunnel, a continuously evolving structure either in normal situations (when the evolution depends on the traffic flows, on the structure conditions, or on the norms and regulations table) or in emergency situations due to accidents.

Salerno University is coordinating and developing the work-package related to safety in road tunnels SITI-SRT (SITI for Safety in Road Tunnel) [17]. In particular the authors have conceived and implemented a system to regulate the vehicle flows approaching the road tunnel to reduce the accident probability in the tunnel. The system is developing in conformity with the European Commission programming rules in terms of tunnel safety, with the purpose of highlighting the critical events prevention factors by acting directly on the users. Specifically the SITI-SRT system gives the users approaching to road tunnels some suggestions about how to drive properly in relation to the infrastructure conditions, traffic conditions, drive style used by the other drivers, etc, either to avoid unintentional human errors or to reduce their consequences. The system is based on a series of telematics portals that monitor and recognize the vehicles approaching the tunnels, estimating the time to arrival at the next check point. Comparing the estimated arrival time with the real one, the system will classify, using a Fuzzy Logic inferential engine, the potentially dangerous behaviors that may increase the accident risks in tunnels, displaying immediately on a VMS (variable message system) set up along the infrastructure an alert message. 
Moreover, knowing the number, the size and the speed of each vehicle approaching the tunnel, the road specifics and the weather conditions, the system calculates dynamically and adaptatively the speed limits both inside and outside the tunnel. The speed limits are displayed on the VMS, whereas inside the tunnel a flashing light, moving with the suggested speed, will show both the speed suggested and the proper safety distance.

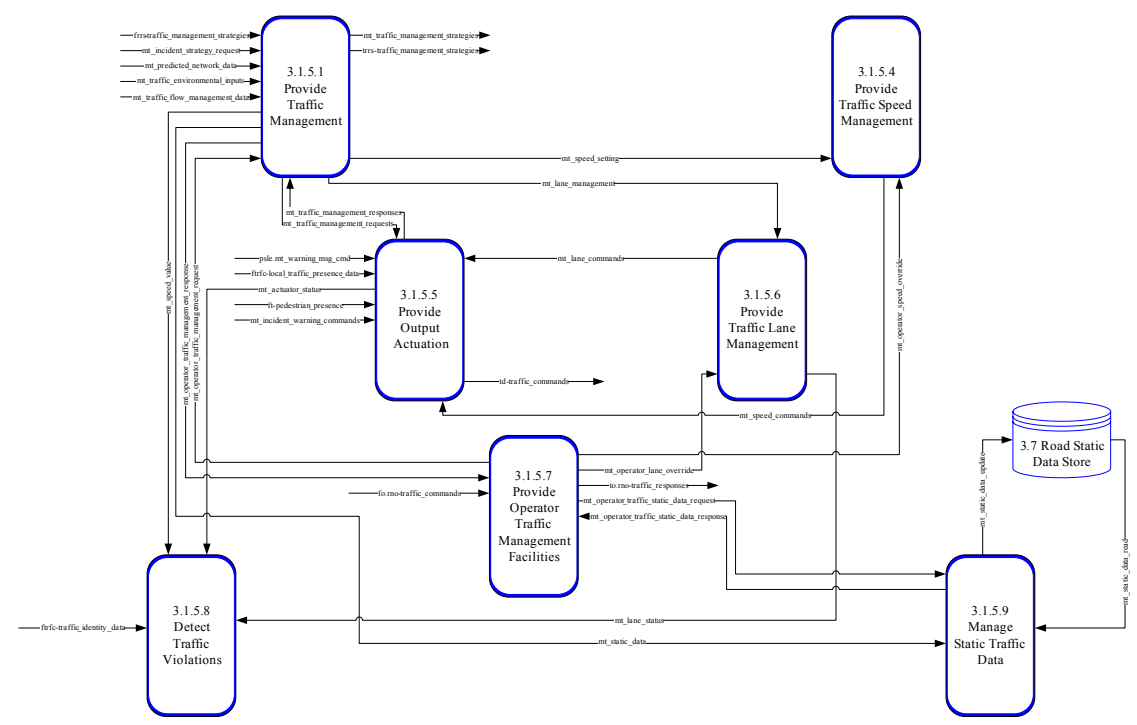

Figure 4: DFD of manage traffic.

From a methodological point of view, the project is one of the first monitoring and traffic control systems based on the ARTIST framework. The use of ARTIST in the design phase has guarantee interoperability, modularity, scalability and integrity of the telematics solution carried out and compliance with the European FRAME Architecture too.

In accordance with ARTIST rules, the logical architecture of SITI-SRT is developed in the following phases:

- project aim and user requirements;

- detection of Users' Needs that respond to the project aim and user requirements;

- detection of Terminators which the system has to interact with;

- detection of Functional Areas, Functions, Sub-functions, able to meet the Users' Needs;

- selection of Data Flows;

- design of the architectural diagram.

The logical architecture, shown in figure 4, is being developed and combines web-centric and agent-oriented technologies with soft-computing methods. In particular, these technologies are used to create a behaviours-predicting model 
that works on a virtual projection of the physical space; a software agent is assigned to each monitored vehicle - the so-called "Vehicle Agent" - whose aim is to classify the drivers' behaviours through observations, predictions and checks.

From the physical point of view, the system merges data coming from video systems installed on telematics portals, efficient calculation systems and VMS panels set up outside the tunnels.

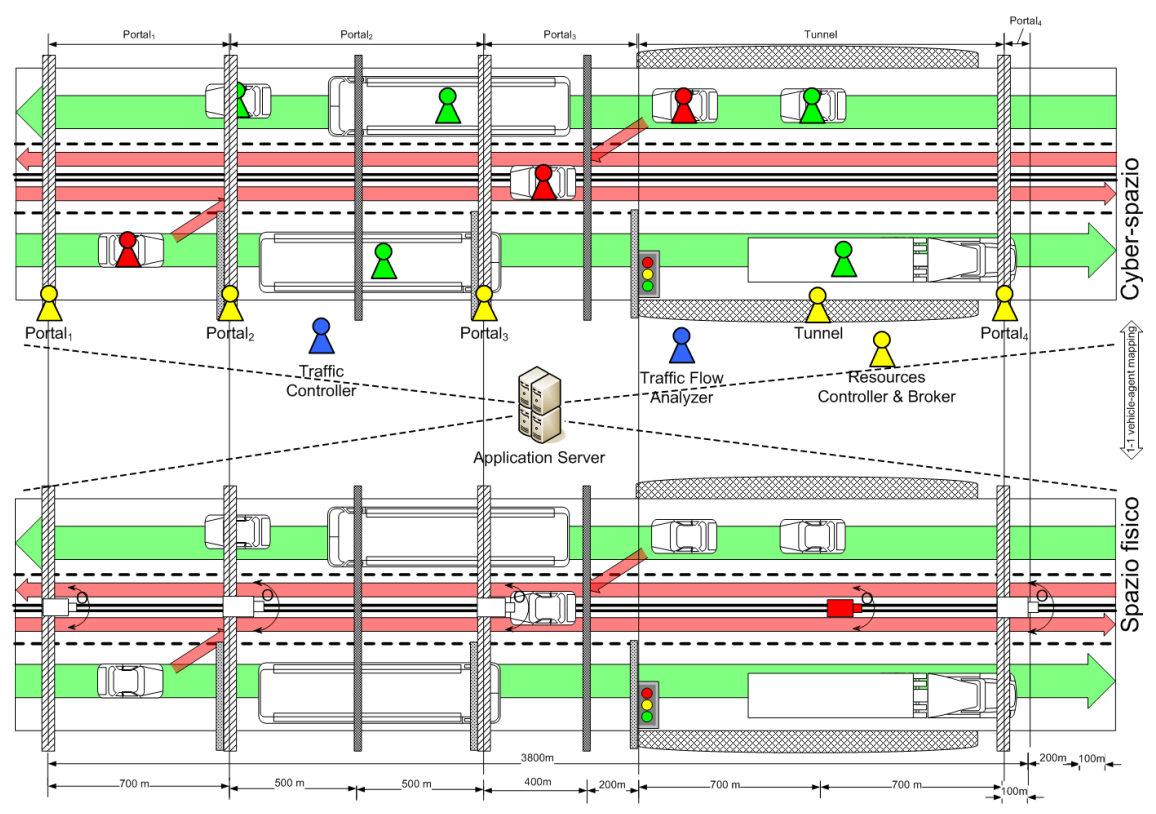

Figure 5: $\quad$ Physical vs. cyber model.

At this moment the system is installed at the University of Salerno for tuning and will be implemented next October in Campania on the SS 145 "Sorrentina", a regional highway linking Naples to Sorrento.

The modular architecture and the system scalability provided by ARTIST will allow any user to add new system extensions merging SITI-SRT with ventilation and lighting monitoring systems in tunnels so as to increase tunnel safety.

\section{Conclusions}

Progress in Information and Communication Technologies (ICT) has led to the spread of telematics, with a consequential fall in price and a rise in reliability of the related devices. Developing new services able to improve transport efficiency and safety has followed.

So as to maximize the positive results related to the spread of Intelligent Transportation Systems, a new approach to such system design and implementation is necessary. In the last decade, many efforts have been made to 
define shared standards for both the logical and the physical telematics architectures for transport, in order to guarantee interoperability, modularity and scalability of the telematics systems.

In this paper two IT systems designed by the authors of the University of Salerno in the fields of Infomobility and Road safety using ARTIST, the Italian ITS architecture issued by the Ministry of Infrastructure and Transport have been described. The projects has been developed using ARTIST and the main peculiarity concerning the design phases and the architectural features has been presented.

\section{Acknowledgements}

The project has been realized with the financial support of the Centro Regionale di Competenza Trasporti of "Regione Campania", of the Assessorato alla Università e Ricerca - Regione Campania and of the Assessorato alle Attività Produttive - Regione Campania.

The authors acknowledge the Mizar Automazione S.p.A. for the support furnished in the implementation phase.

\section{References}

[1] UE Commission, White Book - The European Transportation policy up to 2010: the time of the choices, 2001, ISBN 92-894-0343-8.

[2] Programming and Planning Office of the Italian Ministry of Infrastructures and Transports, Piano Generale dei Trasporti e della Logistica, October 2000.

[3] L. Figueredo, I. Jesus, J.A. Tenreiro Machado, J. R. Ferriera, J.L.M. de Carvalho: Towards the Development of Intelligent Transportation Systems.

[4] L.V. Williams, Industry efforts to standardise the car bus, Proc. of ICCE International Conference on Consumer Electronics, 2002, 18-20 June 2002, page $32-33$.

[5] J. F. Dillenburg, O. Wolfson, P. C. Nelson: The intelligent travel assistant; The IEEE 5th International Conference on Intelligent Transportation System, 3-6 September 2002, Singapore.

[6] A. Shalaby, C. Lyon, T. Sayed, Transferability of travel time models and provision of real-time arrival time information, 2001 IEEE Intelligent transportation Systems Conference Proceedings - Oakland (CA) USA August 25-29,2001

[7] KAREN, available at url: http://www.cordis.lu/telematics/tap_transport/ research/projectsum/karen.html

[8] FRAME-NET, available at url: http://www.frame-online.net/home.htm

[9] European Commission, Planning a modern transportation system - A guide to intelligent transportation system architecture - IST, Frame project.

[10] ACTIF, available at url: http://www.its-actif.org/ 
[11] H. Mongeot, R. Pagny, Case study: developing an ITS System architecture for France, IEE.

[12] Programming and Planning Office of the Italian Ministry of Infrastructure and Transports, ARTIST - Italian Architecture for ITS, available at url: www.its-artist.rupa.it.

[13] Programming and Planning Office of the Italian Ministry of Infrastructure and Transports, ARTIST - Italian Architecture for ITS, available at url: www.its-artist.rupa.it.

[14] V. Calderaro, V. Galdi, A. Piccolo: La gestione telematica del Trasporto Pubblico, published in Italian on the Journal AEIT, ISSN 0013-6131, July-August 2004, page 55-61.

[15] A. Piccolo, V. Galdi: A new architecture for advanced telematics services, Proc. of URBAN Transport 2006 international conference, 12-14 July 2006, Prague (CZ).

[16] Sacripanti, A., SITI (Safety in Tunnel Intelligence): an Italian global project, Proc. of the 7th International IEEE Conference on Intelligent Transportation Systems, 2004, 3-6 October 2004, pages: 521 - 526.

[17] V. Galdi, V. Loia, A. Piccolo, M. Veniero, Fuzzy pro-active agents as key issue to increase traffic safety for next generation tunnels, IEEE International Conference on Fuzzy Systems, Imperial College, London, UK, 23-26 July, 2007. 